\title{
Geographic variation of parathyroidectomy in patients receiving hemodialysis: a retrospective cohort analysis
}

\author{
James B. Wetmore ${ }^{1,2,3^{*}}$, Jiannong Liu' ${ }^{1}$, Paul J. Dluzniewski ${ }^{4}$, Areef Ishani ${ }^{1,3,5}$, Geoffrey A. Block ${ }^{6}$ and Allan J. Collins ${ }^{1,3}$
}

\begin{abstract}
Background: Secondary hyperparathyroidism (SHPT) is associated with adverse outcomes in patients receiving maintenance dialysis. Parathyroidectomy is a treatment for SHPT; whether parathyroidectomy utilization varies geographically in the US is unknown.

Methods: A retrospective cohort analysis was undertaken to identify all patients aged 18 years or older who were receiving in-center hemodialysis between 2007 and 2009, were covered by Medicare Parts A and B, and had been receiving hemodialysis for at least 1 year. Parathyroidectomy was identified from inpatient claims using relevant International Classification of Diseases, Ninth Revision, Clinical Modification procedure codes. Patient characteristics and End-Stage Renal Disease Network (a proxy for geography) were ascertained. Adjusted odds ratios for parathyroidectomy were estimated from a logistic model.
\end{abstract}

Results: A total of 286,569 patients satisfied inclusion criteria, of whom 4435 (1.5\%) underwent PTX. After adjustment for a variety of patient characteristics, there was a 2 -fold difference in adjusted odds of parathyroidectomy between the most- and least-frequently performing regions. Adjusted odds ratios were more than $20 \%$ higher than average in four networks, and more than 20\% lower in four networks.

Conclusions: Parathyroidectomy use varies substantially by geography in the US; the factors responsible should be further investigated.

Keywords: End-stage renal disease, Dialysis, Mineral metabolism, Parathyroidectomy, Secondary hyperparathyroidism

\section{Background}

Secondary hyperparathyroidism (SHPT) is associated with adverse outcomes in patients receiving maintenance dialysis $[1,2]$. Anecdotally, physicians appear to have widely variable criteria regarding which patients they choose to refer for parathyroidectomy, at least in the US. Perhaps reflecting uncertainty over its role, rates of parathyroidectomy have changed substantially over time in recent decades [3]. While guidelines recommend parathyroidectomy in patients with severe SHPT [4], how it might be used most optimally is uncertain. Parathyroidectomy has been shown to be

\footnotetext{
* Correspondence: James.Wetmore@hcmed.org

${ }^{1}$ Chronic Disease Research Group, Minneapolis Medical Research Foundation, 914 South 8th Street, Suite S4.100, Minneapolis, MN 55404, USA

2Division of Nephrology, Hennepin County Medical Center, Minneapolis, MN, USA

Full list of author information is available at the end of the article
}

associated with improved outcomes in some studies $[5,6]$; however, it has also been shown to be associated with mortality, protracted hypocalcemia, and over-suppression of parathyroid hormone (PTH) [7], and its results with regard to mineral metabolic control are often suboptimal [8]. Thus, understanding the differences between hemodialysis patients who do and do not undergo parathyroidectomy may be important. However, the effect of geographic variation, which is associated with a variety of outcomes and care differences in the dialysis population $[9,10]$ has not been examined in the context of parathyroidectomy. We therefore conducted a retrospective cohort study to examine whether parathyroidectomy use varies geographically in the United States. 


\section{Methods}

Using the United States Renal Data System end-stage renal disease database, we identified patients aged 18 years or older who were receiving in-center hemodialysis between 2007 and 2009, were covered by Medicare Part A (inpatient, outpatient, skilled nursing facility, hospice, or home health agency) and Part B (physician/supplier) as primary payer, and had been receiving hemodialysis for at least 1 year. Parathyroidectomy was identified from inpatient claims using International Classification of Diseases, Ninth Revision, Clinical Modification procedure codes 06.81 (complete parathyroidectomy), 06.89 (partial parathyroidectomy and parathyroidectomy not otherwise specified), and 06.95 (parathyroid tissue reimplantation).

Patient characteristics, derived from the end-stage renal disease database Medical Evidence Report and Medicare claims, were assessed on the parathyroidectomy date and on January 1 for non-parathyroidectomy patients. Characteristics included age, sex, race, body mass index, cause of renal disease, dialysis duration, and common comorbid conditions, as have been used previously [11]. Our proxy for geography was US End-Stage Renal Disease Network ( $n=18$, Table 1$)$, geographically based regions designed to facilitate care and monitor

Table 1 End-stage renal disease networks and associate US states

\begin{tabular}{ll}
\hline Network number & States and territories \\
\hline 1 & Connecticut, Maine, Massachusetts, New Hampshire, \\
2 & Rhode Island, Vermont \\
3 & New York \\
4 & Delaware, Pennsylvania \\
5 & District of Columbia, Maryland, Virginia, West Virginia \\
6 & Georgia, North Carolina, South Carolina \\
7 & Florida \\
8 & Alabama, Mississippi, Tennessee \\
9 & Indiana, Kentucky, Ohio \\
10 & Illinois \\
11 & Michigan, Minnesota, North Dakota, South Dakota, \\
12 & Wisconsin \\
13 & lowa, Kansas, Missouri, Nebraska \\
14 & Arkansas, Louisiana, Oklahoma \\
15 & Texas \\
16 & Arizona, Colorado, Nevada, New Mexico, Utah, \\
17 & Wyoming \\
\hline & Alaska, Idaho, Montana, Oregon, Washington \\
& American Samoa, Guam, Mariana Islands, Hawaii, \\
& Northern California \\
&
\end{tabular}

quality on a regional level. Adjusted odds ratios (ORs) and 95\% confidence intervals (CIs) for parathyroidectomy were estimated from a logistic model adjusting for the factors described above. The adjusted ORs for the renal networks were calculated using the whole nation as the reference. All statistical analyses were conducted using SAS software, Version 9.2, SAS Institute Inc., Cary, NC, USA.

\section{Results}

We identified 286,569 patients who satisfied our inclusion criteria, of whom 4435 (1.5\%) underwent parathyroidectomy (Table 2). Parathyroidectomy frequency was 2.3 fold greater, in unadjusted terms, for the least-frequently performing region $(0.97 \%$ of patients, Network 18) compared with the mostfrequently performing region $(2.20 \%$ of patients, Network 6).

Network was associated with substantial variability in likelihood of parathyroidectomy (Fig. 1). Even after adjustment for all characteristics in Table 2, adjusted ORs for parathyroidectomy varied from 0.67 (95\% CIs $0.58-0.78)$ to $1.37(1.17-1.60)$ between the least- and most-frequently performing regions. Adjusted ORs were more than $20 \%$ higher than the national level in four networks and more than $20 \%$ lower in four networks.

In addition, younger age (adjusted OR 1.95, 95\% CI 1.832.08 , vs. age $45-64$ years), female sex $(1.23,1.16-1.30)$, black race $(1.29,1.21-1.37$ vs. white), dialysis duration $>5$ years $(3.70,3.27-4.05$ vs. $1-<3$ years), and atherosclerotic heart disease $(1.15,1.07-1.23)$ were associated with parathyroidectomy $(P<0.001)$. Diabetes $(0.82,0.76-0.89)$ and history of stroke $(0.82,0.74-0.89)$ were inversely associated with parathyroidectomy.

Results for the multivariable model for factors associated with parathyroidectomy are shown in Table 3.

\section{Discussion}

SHPT treatment presents a complex clinical challenge. Practice guidelines provide direction [4] but suffer from lack of randomized clinical trial data, resulting in uncertainty about the benefits and risks of parathyroidectomy. Understanding use of parathyroidectomy is important, given widely varying recent data demonstrating both clinical benefits $[5,6]$, as well as high rates of adverse events and suboptimal mineral metabolic outcomes [7, 8]. Our large retrospective analysis demonstrated substantial geographic variation in parathyroidectomy use. This difference was not driven solely by outliers at the extremes; AORs were $20 \%$ higher or lower than unity in eight Networks. This could reflect regional differences in many potential factors, including provider-related 
Table 2 Characteristics of patients who did and did not undergo parathyroidectomy

\begin{tabular}{|c|c|c|c|c|}
\hline & \multicolumn{2}{|l|}{ PTX } & \multicolumn{2}{|l|}{ Non-PTX } \\
\hline & $n$ & $\%$ & $n$ & $\%$ \\
\hline Total & 4435 & 100 & 282,134 & 100 \\
\hline \multicolumn{5}{|l|}{ Age at PTX, years } \\
\hline $19-44$ & 1764 & 39.8 & 38,830 & 13.8 \\
\hline $45-64$ & 2154 & 48.6 & 110,788 & 39.3 \\
\hline $65-74$ & 410 & 9.2 & 69,550 & 24.7 \\
\hline$\geq 75$ & 107 & 2.4 & 62,966 & 22.3 \\
\hline \multicolumn{5}{|l|}{ Race } \\
\hline White & 1685 & 38.0 & 156,638 & 55.5 \\
\hline Black & 2551 & 57.5 & 108,246 & 38.4 \\
\hline Other & 199 & 4.5 & 17,250 & 6.1 \\
\hline \multicolumn{5}{|l|}{ Sex } \\
\hline Male & 2298 & 51.8 & 155,257 & 55.0 \\
\hline Female & 2137 & 48.2 & 126,877 & 45.0 \\
\hline \multicolumn{5}{|l|}{ ESRD primary cause } \\
\hline Diabetes & 1013 & 22.8 & 128,202 & 45.4 \\
\hline Hypertension & 1462 & 33.0 & 81,231 & 28.8 \\
\hline Glomerulonephritis & 934 & 21.1 & 27,250 & 9.7 \\
\hline Other/unknown/missing & 1026 & 23.1 & 45,451 & 16.1 \\
\hline \multicolumn{5}{|l|}{$\mathrm{BMl}, \mathrm{kg} / \mathrm{m}^{2}$} \\
\hline$<18$ & 151 & 3.4 & 8074 & 2.9 \\
\hline $18-<25$ & 1217 & 27.4 & 88,838 & 31.5 \\
\hline $25-<30$ & 1026 & 23.1 & 78,938 & 28.0 \\
\hline $30-<35$ & 772 & 17.4 & 49,310 & 17.5 \\
\hline $35-<40$ & 517 & 11.7 & 25,987 & 9.2 \\
\hline$\geq 40$ & 536 & 12.1 & 23,383 & 8.3 \\
\hline Missing & 216 & 4.9 & 7604 & 2.7 \\
\hline \multicolumn{5}{|l|}{ Dialysis duration, years } \\
\hline $1-<3$ & 538 & 12.1 & 151,778 & 53.8 \\
\hline $3-<5$ & 970 & 21.9 & 58,341 & 20.7 \\
\hline$>5$ & 2927 & 66.0 & 72,015 & 25.5 \\
\hline \multicolumn{5}{|l|}{ Comorbidities } \\
\hline Diabetes & 1954 & 44.1 & 185,029 & 65.6 \\
\hline ASHD & 1542 & 34.8 & 131,678 & 46.7 \\
\hline CHF & 1973 & 44.5 & 144,792 & 51.3 \\
\hline CVA/TIA & 522 & 11.8 & 57,532 & 20.4 \\
\hline PVD & 1389 & 31.3 & 112,972 & 40.0 \\
\hline Dysrhythmia & 1057 & 23.8 & 77,320 & 27.4 \\
\hline Other cardiac disease & 1623 & 36.6 & 91,955 & 32.6 \\
\hline \multicolumn{5}{|l|}{ Network } \\
\hline 1 & 151 & 3.4 & 9407 & 3.3 \\
\hline 2 & 192 & 4.3 & 16,808 & 6.0 \\
\hline 3 & 156 & 3.5 & 11,887 & 4.2 \\
\hline 4 & 118 & 2.7 & 11,689 & 4.1 \\
\hline 5 & 260 & 5.9 & 17,080 & 6.1 \\
\hline 6 & 667 & 15.0 & 29,663 & 10.5 \\
\hline
\end{tabular}


Table 2 Characteristics of patients who did and did not undergo parathyroidectomy (Continued)

\begin{tabular}{|c|c|c|c|c|}
\hline 7 & 253 & 5.7 & 16,076 & 5.7 \\
\hline 8 & 364 & 8.2 & 17,060 & 6.1 \\
\hline 9 & 293 & 6.6 & 21,152 & 7.5 \\
\hline 10 & 154 & 3.5 & 11,977 & 4.3 \\
\hline 11 & 252 & 5.7 & 18,814 & 6.7 \\
\hline 12 & 199 & 4.5 & 11,188 & 4.0 \\
\hline 13 & 254 & 5.7 & 12,073 & 4.3 \\
\hline 14 & 487 & 11.0 & 27,892 & 9.9 \\
\hline 15 & 182 & 4.1 & 12,016 & 4.3 \\
\hline 16 & 139 & 3.1 & 7254 & 2.6 \\
\hline 17 & 136 & 3.1 & 11,860 & 4.2 \\
\hline 18 & 178 & 4.0 & 18,238 & 6.5 \\
\hline
\end{tabular}

$A S H D$ atherosclerotic heart disease, $B M I$ body mass index, CHF congestive heart failure, CVA/TIA cerebrovascular accident/transient ischemic attack, ESRD end-stage renal disease, PTX parathyroidectomy, PVD peripheral vascular disease

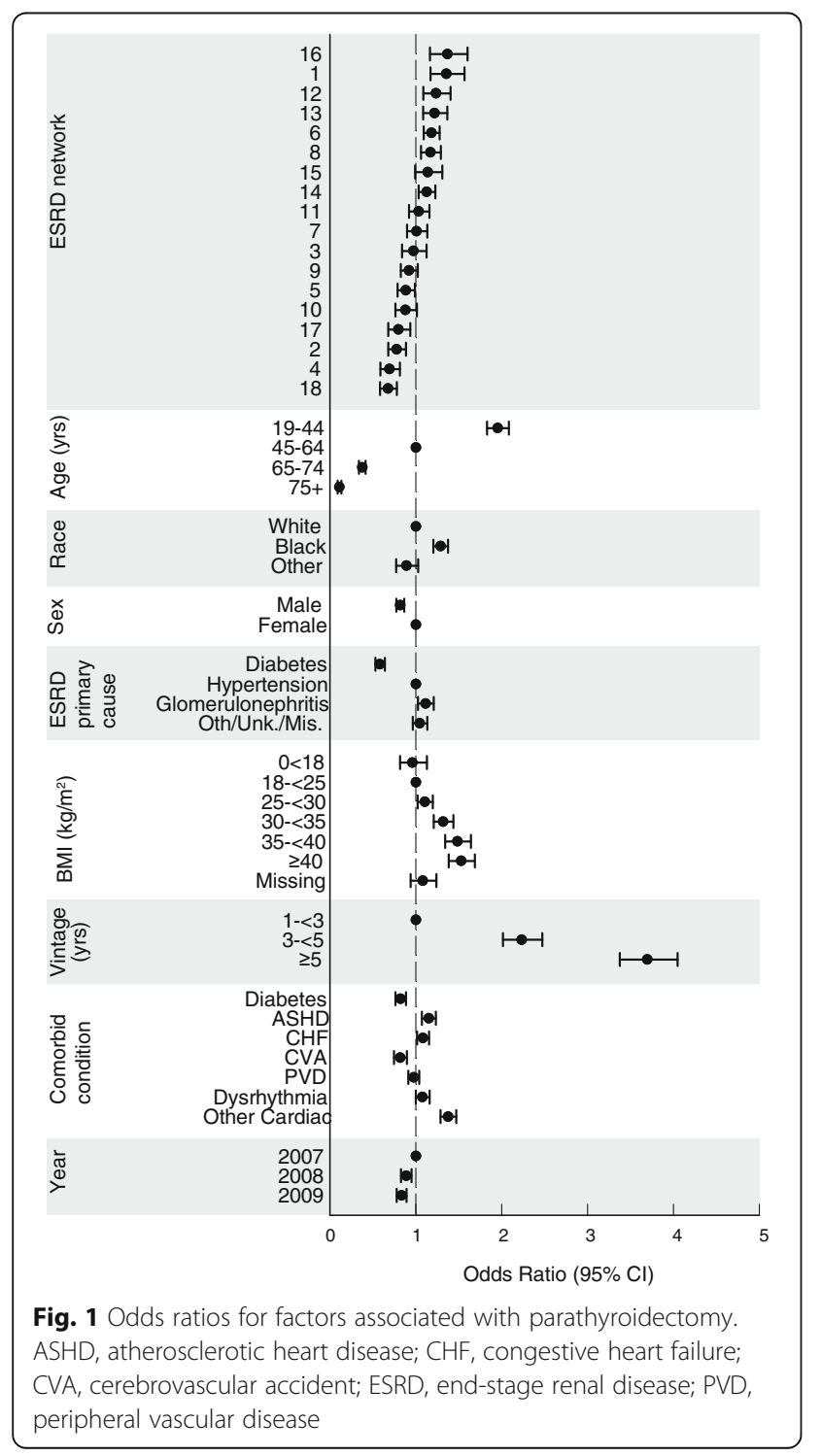

ones such as particular treatment approaches instilled during training, access to qualified parathyroid surgeons, or local "cultures" of treatment, all of which might play substantial roles in how care is differentially rendered [12].

Certain demographic factors, specifically younger age and black race, were also associated with likelihood of parathyroidectomy; this was not unexpected given that both of these factors have been previously reported to be associated with more severe SHPT [2, 13]. Dialysis duration was also associated with parathyroidectomy, possibly because the changes that characterize severe parathyroid gland dysregulation may take many years to develop [14]; alternatively, providers may be resorting to parathyroidectomy only after prolonged attempts at other interventions prove fruitless. The inverse associations between older age and history of stroke and parathyroidectomy may reflect poor surgical candidacy in the provider's estimation.

Our study was limited by lack of patient-level data about degree of PTH control, SHPT therapies employed, or other SHPT markers such as serum calcium and phosphorus, which likely predict the parathyroidectomy decision. For example, use of cinacalcet, which has been shown to reduce rates of parathyroidectomy [15], might vary widely by region, although we have no $a$ priori reason to posit this and it seems unlikely to account for a more than 2-fold variation in parathyroidectomy rates. Additionally, we lack information about geographic variation in renal transplant; fewer individuals in areas in which early transplant occurs more commonly might be at risk of developing severe SHPT and subsequently undergoing parathyroidectomy. Again, given the magnitude of variation between the most- and least-frequently parathyroidectomy performing regions, case mix alone is unlikely to fully account for it. 
Table 3 Multivariable model for factors associated with parathyroidectomy

\begin{tabular}{l} 
Factors \\
\hline Age at PTX, years \\
$19-44$ \\
$45-64$ \\
$65-74$ \\
$\geq 75$ \\
Race \\
White \\
Black \\
Other \\
Sex \\
Male \\
Female \\
ESRD primary cause \\
Diabetes \\
Hypertension \\
Glomerulonephritis \\
Other/unknown/missing \\
BMI, kg/m ${ }^{2}$ \\
$<18$ \\
$18-<25$ \\
$25-<30$ \\
$30-<35$ \\
$35-<40$ \\
$\geq 40$ \\
Missing \\
(1)
\end{tabular}

Dialysis duration, years

$$
\begin{aligned}
& 1-<3 \\
& 3-<5 \\
& \geq 5
\end{aligned}
$$

Comorbid conditions

Diabetes
ASHD
CHF
CVA/TIA
PVD
Dysrhythmia
Other cardiac disease

ESRD Network

$$
\begin{aligned}
& 16 \\
& 1 \\
& 12 \\
& 13 \\
& 6
\end{aligned}
$$

$\operatorname{HR}(95 \% \mathrm{Cl}) \quad P$

$1.95(1.83-2.08)$

1 (Referent)

$0.37(0.34-0.42)$

$0.11(0.09-0.13)$

1 (Referent)

$1.29(1.21-1.37)$

$0.89(0.77-1.03)$

$0.82(0.77-0.87)$

1 (Referent)

$0.58(0.53-0.64)$

1 (Referent)

$1.11(1.02-1.21)$

$1.04(0.96-1.13)$

$0.96(0.82-1.13)$

1 (Referent)

$1.10(1.02-1.20)$

$1.32(1.21-1.44)$

$1.48(1.34-1.64)$

$1.53(1.38-1.69)$

$1.08(0.94-1.24)$

1 (Referent)

$2.23(2.02-2.47)$

$3.70(3.37-4.05)$

$<0.001$

$<0.001$

$0.82(0.76-0.89)$

$1.15(1.07-1.23)$

$1.08(1.01-1.15)$

$0.82(0.74-0.89)$

$0.97(0.91-1.04)$

$1.08(1.00-1.16)$

1.37 (1.29-1.47)

$1.37(1.17-1.60)$

1.35 (1.17-1.57)

1.24 (1.09-1.40)

$1.24(1.08-1.37)$

$1.18(1.09-1.28)$

$<0.001$

$<0.001$

0.019

$<0.001$

0.42

0.058

$<0.001$

0.001
Table 3 Multivariable model for factors associated with parathyroidectomy (Continued)

\begin{tabular}{lll}
\hline 8 & $1.17(1.06-1.29)$ & 0.002 \\
15 & $1.14(0.99-1.31)$ & 0.067 \\
14 & $1.13(1.03-1.23)$ & 0.008 \\
11 & $1.03(0.92-1.16)$ & 0.60 \\
7 & $1.01(0.90-1.13)$ & 0.91 \\
3 & $0.97(0.84-1.12)$ & 0.69 \\
9 & $0.92(0.83-1.02)$ & 0.12 \\
5 & $0.88(0.79-0.99)$ & 0.032 \\
10 & $0.88(0.76-1.01)$ & 0.070 \\
17 & $0.80(0.68-0.93)$ & 0.005 \\
2 & $0.78(0.68-0.88)$ & $<0.001$ \\
4 & $0.69(0.59-0.82)$ & $<0.001$ \\
18 & $0.67(0.58-0.78)$ & $<0.001$ \\
Year & & \\
2007 & $1($ Referent $)$ & \\
2008 & $0.89(0.83-0.95)$ & 0.001 \\
2009 & $0.83(0.78-0.89)$ & $<0.001$ \\
\hline $\begin{array}{l}\text { ASHD atherosclerotic heart disease, BMI body mass index, CHF congestive heart } \\
\text { failure, Cl confidence interval, CVANTA cerebrovascular accident/transient ischemic } \\
\text { attack, ESRD end-stage renal disease, HR hazard ratio, PTX parathyroidectomy, } \\
P V D \text { peripheral vascular disease }\end{array}$ &
\end{tabular}

\section{Conclusion}

Even after adjustment of a variety of case-mix variables, use of parathyroidectomy varies substantially by geography in the US; the factors responsible should be further investigated. Given recent information about the potential risks associated with parathyroidectomy [7, 8], the factors responsible for shaping the decision to undertake it should also be the subject of future investigation.

\section{Abbreviations}

Cl: Confidence interval; OR: Odds ratio; PTH: Parathyroid hormone;

SHPT: Secondary hyperparathyroidism

\section{Acknowledgments}

The data reported here have been supplied by the United States Renal Data System. The interpretation and reporting of these data are the responsibility of the authors and in no way should be seen as an official policy or interpretation of the US Government. The authors thank Chronic Disease Research Group colleagues Delaney Berrini, BS, for manuscript preparation and figure design and Nan Booth, MSW, MPH, ELS, for manuscript editing.

\section{Funding}

$<0.001 \quad$ This study was supported by a research contract from Amgen Inc., Thousand

$<0.001$ Foundation authors to have final determination of manuscript content

$0.001 \quad$ Availability of data and materials

$<0.001$ Data were obtained from the United States Renal Data System (USRDS), which is publically available and free of charge from the USRDS Coordinating Center. 


\section{Authors' contributions}

Substantial contributions to conception and design, or acquisition of data, or analysis and interpretation of data: JBW, JL, PJD, Al, GAB, AJC; drafting the manuscript or revising it critically for important intellectual content: JBW, JL, PJD, Al, GAB, AJC; final approval of the version to be published: JBW, JL, PJD, $A \mathrm{Al}, \mathrm{GAB}, \mathrm{AJC}$; sufficient participation in the work to take public responsibility for appropriate portions of the content: JBW, JL, PJD, Al, GAB, AJC; agree to be accountable for all aspects of the work in ensuring that questions related to the accuracy or integrity of any part of the work are appropriately investigated and resolved: JBW, JL, PJD, Al, GAB, AJC. All authors read and approved the final manuscript.

\section{Competing interests}

James B. Wetmore, Jiannong Liu, Areef Ishani, and Allan J. Collins are employed by the Chronic Disease Research Group, which receives research support from Amgen. Dr. Liu has provided consultation to Daiichi Sankyo. Dr. Dluzniewski is employed by Amgen and owns Amgen stock. Dr. Collins has provided consultation to Amgen, Relypsa, DaVita Clinical Research, NxStage, Keryx, and ZS Pharma. Geoffrey A. Block is employed by Denver Nephrologists, and has provided consultation to, and received research support from, Amgen.

\section{Consent for publication}

Not applicable.

\section{Ethics approval and consent to participate}

We applied to and received approval from the Human Subjects Research Committee of the Hennepin County Medical Center/Hennepin Healthcare System, Inc., Minneapolis, Minnesota.

\section{Author details}

${ }^{1}$ Chronic Disease Research Group, Minneapolis Medical Research Foundation, 914 South 8th Street, Suite 54.100, Minneapolis, MN 55404, USA. ${ }^{2}$ Division of Nephrology, Hennepin County Medical Center, Minneapolis, MN, USA. ${ }^{3}$ Department of Medicine, University of Minnesota, Minneapolis, MN, USA. ${ }^{4}$ Center for Observational Research, Amgen Inc, Thousand Oaks, CA, USA. ${ }^{5}$ Section of Renal Diseases and Hypertension, Minneapolis Veterans Administration Health Care System, Minneapolis, MN, USA. ${ }^{6}$ Denver Nephrology Clinical Research Division, Denver, CO, USA.

Received: 14 June 2016 Accepted: 24 November 2016 Published online: 29 November 2016

\section{References}

1. Tentori F, Blayney MJ, Albert JM, Gillespie BW, Kerr PG, Bommer J, et al. Mortality risk for dialysis patients with different levels of serum calcium, phosphorus, and PTH: the Dialysis Outcomes and Practice Patterns Study (DOPPS). Am J Kidney Dis. 2008:52:519-30.

2. Kalantar-Zadeh K, Miller JE, Kovesdy CP, Mehrotra R, Lukowsky LR, Streja E, et al. Impact of race on hyperparathyroidism, mineral disarrays, administered vitamin D mimetic, and survival in hemodialysis patients. J Bone Miner Res. 2010:25:2724-34.

3. Kim SM, Long J, Montez-Rath ME, Leonard MB, Norton JA, Chertow GM. Rates and Outcomes of Parathyroidectomy for Secondary Hyperparathyroidism in the United States. Clin J Am Soc Nephrol. 2016;11:1260-7.

4. Kidney Disease: Improving Global Outcomes (KDIGO) CKD-MBD Work Group. KDIGO clinical practice guideline for the diagnosis, evaluation, prevention, and treatment of Chronic Kidney Disease-Mineral and Bone Disorder (CKD-MBD). Kidney Int Suppl. 2009:76 Suppl 113:S1-130.

5. Goldenstein PT, Elias RM, Pires de Freitas do Carmo L, Coelho FO, Magalhaes $L P$, Antunes $G L$, et al. Parathyroidectomy improves survival in patients with severe hyperparathyroidism: a comparative study. PLoS One. 2013;8:e68870

6. Komaba H, Taniguchi M, Wada A, Iseki K, Tsubakihara Y, Fukagawa M. Parathyroidectomy and survival among Japanese hemodialysis patients with secondary hyperparathyroidism. Kidney Int. 2015;88:350-9.

7. Ishani A, Liu J, Wetmore JB, Lowe KA, Do T, Bradbury BD, et al. Clinical outcomes after parathyroidectomy in a nationwide cohort of patients on hemodialysis. Clin J Am Soc Nephrol. 2015;10:90-7.
8. Wetmore JB, Liu J, Do TP, Lowe KA, Ishani A, Bradbury BD, et al. Changes in secondary hyperparathyroidism-related biochemical parameters and medication use following parathyroidectomy. Nephrol Dial Transplant. 2016;31:103-11.

9. Erickson KF, Tan KB, Winkelmayer WC, Chertow GM, Bhattacharya J. Variation in nephrologist visits to patients on hemodialysis across dialysis facilities and geographic locations. Clin J Am Soc Nephrol. 2013;8:987-94.

10. Sood MM, Manns B, Dart A, Hiebert B, Kappel J, Komenda P, et al. Variation in the level of eGFR at dialysis initiation across dialysis facilities and geographic regions. Clin J Am Soc Nephrol. 2014;9:1747-56.

11. Liu J, Huang Z, Gilbertson DT, Foley RN, Collins AJ. An improved comorbidity index for outcome analyses among dialysis patients. Kidney Int. 2010;77:141-51.

12. Wennberg J, Gittelsohn A. Variations in medical care among small areas. Sci Am. 1982;246:120-34.

13. Wolf M, Betancourt J, Chang Y, Shah A, Teng M, Tamez H, et al. Impact of activated vitamin $D$ and race on survival among hemodialysis patients. J Am Soc Nephrol. 2008;19:1379-88.

14. Slatopolsky E, Brown A, Dusso A. Pathogenesis of secondary hyperparathyroidism. Kidney Int Suppl. 1999;73:S14-9.

15. EVOLVE Trial Investigators, Chertow GM, Block GA, Correa-Rotter R, Drueke TB, Floege J, et al. Effect of cinacalcet on cardiovascular disease in patients undergoing dialysis. N Engl J Med. 2012;367:2482-94.

\section{Submit your next manuscript to BioMed Central and we will help you at every step:}

- We accept pre-submission inquiries

- Our selector tool helps you to find the most relevant journal

- We provide round the clock customer support

- Convenient online submission

- Thorough peer review

- Inclusion in PubMed and all major indexing services

- Maximum visibility for your research

Submit your manuscript at www.biomedcentral.com/submit
Biomed Central 